\title{
Dose-Adjusted Beta-Lactam Antibiotic-Induced Encephalopathy in a Patient with End-Stage Renal Impairment: A Case Report
}

\author{
Chris Anthony ${ }^{a}$, Meenal Sharma ${ }^{a}$, Roberto Spina ${ }^{a}$, Peter S Macdonalda, Jacob Sevastos ${ }^{b}$ \\ aDepartment of Cardiology, St Vincent's Hospital, Sydney, Australia \\ ${ }^{b}$ Department of Nephrology, St Vincent's Hospital, Sydney, Australia
}

Doi: 10.12890/2015_000172 - European Journal of Case Reports in Internal Medicine - C EFIM 2015

Received: $16 / 12 / 2014$

Accepted: 06/01/2015

Published: $11 / 02 / 2015$

How to cite this article: Anthony C, Sharma M, Spina R, Macdonald PS, Sevastos J. Dose-adjusted beta-lactam antibiotic-induced encephalopathy in a patient with end-stage renal impairment: a case report. EJCRIM 2015;2:doi: 10.12890/2015_000172

Conflicts of Interests: The authors declare that they have no conflicts of interest in this research

This article is licensed under a Commons Attribution Non-Commercial 4.0 License

\begin{abstract}
Introduction: Despite adherence to current guidelines regarding dose adjustment and drug-level monitoring, beta-lactam-induced encephalopathy can still occur in the setting of chronic renal impairment.
\end{abstract}

Case Report:We report what we believe is the first case of piperacillin- and tazobactam-induced encephalopathy in a patient with pre-existing cefepime-induced encephalopathy in the context of end-stage kidney disease despite adequate dose adjustment for renal impairment.

\section{LEARNING POINTS}

- Beta-lactam antibiotics may result in acute encephalopathy in susceptible patients.

- Patients with renal impairment are especially vulnerable to beta-lactam-induced encephalopathy.

- Appropriate renal adjustment of dosing may still result in the development of encephalopathy in patients with renal impairment.

\section{KEYWORDS \\ Cefepime encephalopathy}

\section{INTRODUCTION}

Beta-lactam antibiotics given intravenously to patients with renal impairment can result in neurotoxicity that manifests as an acute decrease in consciousness, myoclonic jerks and seizure-type activity including non-convulsive status epilepticus ${ }^{[1-12]}$. Chronic kidney disease affects the drug elimination of beta-lactams and pharmacokinetic processes involved in its clearance. This makes the alteration of drug dosing with respect to individual creatinine clearance necessary ${ }^{[13]}$. Despite adherence to current guidelines regarding dose adjustment and drug-level monitoring, beta-lactam-induced encephalopathy can still occur in the setting of chronic renal impairment ${ }^{[5,7]}$.

We report what we believe is the first case of piperacillin- and tazobactam-induced encephalopathy in a patient with pre-existing cefepimeinduced encephalopathy in the context of end-stage kidney disease despite adequate dose adjustment for renal impairment.

\section{CASE REPORT}

A 45-year-old female with a complex history of teenage ovarian and thyroid malignancy requiring chemo-radiotherapy, restrictive cardiomyopathy and end-stage chronic kidney disease requiring long-term peritoneal dialysis presented to our institution with severe hospital-acquired pneumonia and a functional ileus leading to multisystem organ dysfunction requiring intensive care admission. A year prior to this admission, she had a documented episode of acute encephalopathy post-cefepime initiation for a lower respiratory tract infection. Her creatinine at time of admission was $410 \mathrm{mmol} / \mathrm{l}$ with urea of $22.6 \mathrm{mmol} / \mathrm{l}$. She was on a twice daily exchange regimen with $2.5 \%$ icodextrin solution as part of her peritoneal dialysis regimen. She was commenced on piperacillin and tazobactam at a renally adjusted dose of $4.5 \mathrm{~g}$ bd for a period of 5 days, when she began to experience fluctuations in her conscious state with a recorded Glasgow Coma Scale of 12. At this point, the piperacillin and tazobactam were ceased and a subsequent level for the antibiotic was ordered. On Day 2, her piperacillin level was 445 mg/l, Day 3130 mg/l, Day 49 mg/l and Day 51.5 mg/l. Her tazobactam levels were $62.3,15.5$ mg/l, 1.5 mg/l and $0.5 \mathrm{mg} / \mathrm{l}$ on those days.

She was also transitioned onto continuous venovenous haemodiafiltration at this point to help facilitate drug clearance. Her cognitive state 
continued to deteriorate and $24 \mathrm{~h}$ later her GCS had dropped to 3, requiring urgent intubation. Her encephalopathy persisted, with a failure to extubate her on Day 5 post-onset of encephalopathy. Unfortunately, she deteriorated further and succumbed to her illness on Day 10 of her ICU admission.

\section{DISCUSSION}

In patients with renal failure, penicillin- and cephalosporin-based antibiotics can accumulate in both the blood and cerebrospinal fluid, reaching toxic concentrations ${ }^{[1,2,4,14]}$. Current practice advocates dose-related adjustment of both penicillin and cefepime based on standard algorithms derived from individual creatinine clearance ${ }^{[13]}$. In this case, we made the appropriate renal dose adjustment prior to dosing of her penicillin-based antibiotic, however encephalopathy was still induced. This has been documented in several other studies, where doserelated adjustment still induced neurological side effects post-administration ${ }^{[1-4]}$. Another interesting point is that there appeared to be no temporal relationship between previous exposure to piperacillin and tazobactam and the development of her encephalopathy, as she had received similar renal adjusted doses in the past without similar detrimental effects. This may be related to the degree of residual renal function impacting the risk of neurotoxicity, however there are no active assays to quantify this risk based on serum drug concentration ${ }^{[6]}$. Penicillin and piperacillin with tazobactam-induced encephalopathy has been documented in the literature, however less extensively than cefepime-induced encephalopathy ${ }^{[7,8,10-19]}$. A study by Chapuis et al. ${ }^{[16]}$ looked prospectively at patients in intensive care who received renally adjusted doses of cefepime based on their calculated creatinine clearance and demonstrated that the plasma cefepime concentrations varied by two- to three-fold at peak levels and up to 40 -fold at trough levels. This is potentially why our patient developed acute encephalopathy with cephalosporin use despite active measurement of her cefepime levels. In another retrospective review, of 100 patients in a critical care setting requiring cefepime intravenously, Fugate et al. showed that $29 \%$ developed neurologic symptoms despite a standard dose reduction based on their creatinine clearance ${ }^{[5]}$. Cefepime and its potential to reduce seizure threshold in patients with renal impairment was specifically emphasized in a United States Food and Drug Administration safety announcement in $2012^{[15]}$ due to approximately 60 cases of cefepime-associated non-convulsive status epilepticus and ongoing seizure activity that resulted in the death of at least 1 of those reported. This emphasizes the difficulty in predicting adverse outcomes even with appropriate pharmacokinetic dose adjustment in patients with pre-existing renal impairment with the use of cefepime ${ }^{[7,14]}$.

Of note, neurotoxicity can also occur despite concurrent haemodialysis ${ }^{[14,16,18]}$. One would expect the neurological symptoms to improve after adequate clearance of the drug if on renal replacement therapy, as was the case with our patient, however predicting which groups of patients may develop encephalopathy and when remains entirely elusive.

\section{CONCLUSION}

Beta-lactam neurotoxicity affects patients critically ill with chronic kidney disease. It most commonly occurs when dose adjustments according to creatinine clearance are not performed, but can occur despite dose adjustment and renal replacement therapy in some patients, as described in this case, with significant detrimental effects. A more accurate method of measuring serum penicillin and cefepime levels is required to prevent the development of beta-lactam-induced encephalopathy, especially in patients with impaired renal function.

\section{REFERENCES}

Bloomer A, Barton L, Maddock RK Jr. Penicillin-induced encephalopathy in uremic patients, JAMA 1967;200:121-123.

2. Fossieck B, Parker RH. Neurotoxicity during intravenous infusion of penicillin. A review, J Clin Pharma 1974;14:504-512.

3. Marks MI, Hirshfeld S. Neurotoxicity of penicillin, N Engl J Med 1968;279:1002-1003.

Tong MK, Siu YP, Yung CY, Kwan TH. Piperacillin/tazobactam-induced acute delirium in a peritoneal dialysis patient, Nephrol Dial Transplant 2004;19:1341.

Gibson TP, Demetriades JL, Bland JA. Imipenem/cilastatin: pharmacokinetic profile in renal insufficiency, Am J Med 1985;78:54-61.

Sanders WE Jr, Sanders CC. Piperacillin/tazobactam: a critical review of the evolving clinical literature, Clin Infect Dis 1996;22:107-123.

Fugate JE, Kalimullah EA, Hocker SE, Clark SL, Wijdicks EF, Rabinstein AA. Cefepime neurotoxicity in the intensive care unit: a cause of severe, underappreciated encephalopathy, Crit Care 2013;17:R264. Gangireddy VG, Mitchell LC, Coleman T. Cefepime neurotoxicity despite renal adjusted dosing, Scand J Infect Dis 2011;43:827-829.

Munar M, Singh H. Drug dosing adjustments in patients with chronic kidney disease, Am Fam Physician 2007;75:1487-1496.

9. Munar M, Singh H. Drug dosing adjustments in patients with chronic kidney disease, Am Fam Physician 2007;75:1487-1496.

10. Bresson J, Paugam-Burtz C, Josserand J, Bardin C, Mantz J, Pease S. Cefepime overdosage with neurotoxicity recovered by high-volume haemofiltration, J Antimicrob Chemother 2008;62:849-850. Intensive Care Med 2002;28:214-217.

12. Garces EO, de Azambuja MFA, da Silva D, Bragatti JA, Jacoby T, Thome FS. Renal failure is a risk factor for cefepime-induced encephalopathy, J Nephrol 2008;21:526-534.

13. Abanades S, Nolla J, Rodríguez-Campello A, Pedro C, Valls A, Farré M. Reversible coma secondary to cefepime neurotoxicity, Ann Pharmacother 2004;38:606-608.

14. Sonck J, Laureys G, Verbeelen D. The neurotoxicity and safety of treatment with cefepime in patients with renal failure, Nephrol Dial Transplant 2008;23:966-970.

15. Durand-Maugard C, Lemaire-Hurtel AS, Gras-Champel V, Hary L, Maizel J, Prud'homme-Bernardy A et al. Blood and CSF monitoring of cefepime-induced neurotoxicity: nine case reports, J Antimicrob Chemother 2012;67:1297-1299.

16. Smith NL, Freebairn RC, Park MA, Wallis SC, Roberts JA, Lipman J. Therapeutic drug monitoring when using cefepime in continuous renal replacement therapy: seizures associated with cefepime, Crit Care Resusc 2012;14:312-315.

17. FDA Drug Safety Communication: Cefepime and risk of seizure in patients not receiving dosage adjustments for kidney impairment.U.S. Department of Health and Human Services. Available at http://www. fda.gov/Drugs/DrugSafety/ucm309661.htm.

18. Chapuis TM, Giannoni E, Majcherczyk PA, Chioléro R, Schaller MD, Berger MM et al. Prospective monitoring of cefepime in intensive care unit adult patients, Crit Care 2010;14:R51.

19. Barradell LB, Bryson HM. Cefepime. A review of its antibacterial activity, pharmacokinetic properties and therapeutic use, Drugs 1994;47:471-505. 